\title{
Human Subject Research
}

National Cancer Institute

\section{Source}

National Cancer Institute. Human Subject Research. NCI Thesaurus. Code C41385.

A study that has gone beyond the laboratory research and the testing that can be done with experimental animals, and needs to involve humans if it is to be continued at all. Under current law, usually the testing of a new pharmaceutical product or medical device on humans is mandatory. The concept also refers to population-based research in which an investig ator directly interacts with individuals. 